УДК 330.111

\title{
ТАРИФЫ НА ЭЛЕКТРОЭНЕРГИЮ ДЛЯ НАСЕЛЕНИЯ: ЗАРУБЕЖНЫЙ ОПЫТ (ПОРТУГАЛИЯ)
}

\author{
Н.А. ГОЛУБОВА \\ аспирант кафедры «Экономика строительства»
}

Белорусского национального технического университета, г. Минск

\begin{abstract}
Аннотация
Ценообразование тарифов на электроэнергию для населения является вопросом первостепенной важности для любого государства. Республика Беларусь находится в стадии перехода к экономически обоснованным тарифам. В статье изложен опьт Португалии, как государства, давно начавщего прочесс интеграчии энергетических рынков и перехода на свободные тарифы, который имеет ряд особенностей и подлежит исследованию на предмет техник и методологий.

Ключевые слова: энергетика, тарифы, население, электроэнергия, иена, энергореформа.

Abstract

Pricing of electricity tariffs for the population is a matter of paramount importance for any country. Republic of Belarus is now in the process of transition to economically justified tariffs. The article describes the experience of Portugal, as a state that has begun the process of integration of the energy markets and the transition to free prices long time ago, which has a number of features and is to be the studied on the subject of techniques and methodologies.
\end{abstract}

Keywords: energy market, rates, population, electricity power, price, energy reform.

\section{ВВЕДЕНИЕ}

Уровень жизни, уровень благосостояния населения - это степень удовлетворения материальных и духовных потребностей людей массой товаров и услуг, используемых в единицу времени. Большое значение в оценке уровня жизни играют коммунальные услуги. В Республике Беларусь десятилетиями существует система перекрестного субсидирования тарифов, когда для населения устанавливаются субсидируемые тарифы, обеспечивающие покрытие от $20 \%$ до $90 \%$ стоимости коммунальных услуг. 
Перспектива поэтапного повышения тарифов для населения и выход на $100 \%$ оплату стоимости коммунальных услуг затрагивает интересы каждого жителя. Опыт других стран в формировании тарифной политики и управлением жилищно-коммунальными услугами имеет большое значение для поиска путей развития тарифной системы Республики Беларусь, оценки ее преимуществ и недостатков. Изучению системы оплаты коммунальных услуг в Португалии посвящена данная статья.

\section{РЕЗУЛЬТАТЫ И ИХ ОБСУЖДЕНИЕ}

Республика Беларусь и Португалия имеют ряд схожих экономических показателей, несмотря на то, что находятся на разных концах европейского континента. Так население Португалии в 10799270 человек (2013) размещается на вдвое меньшей территории, чем население Республики Беларусь 9498700 (2015). По данным ООН индекс человеческого развития португальцев находится на 43 месте в мире, а белорусов - на 53. ВВП на душу населения в Португалии составляет 22232 долл. США, что на 20,7\% выше белорусского уровня (17 620 долл. США) [1].

Однако в энергетической сфере наблюдаются кардинальные отличия, наглядно представленные на рисунке 1. В Португалии используется много различных источников энергии, причем $24 \%$ - это возобновляемые источники энергии. Энергетическая безопасность Республики Беларусь на $88 \%$ зависит от поставок природного газа, а возобновляемые источники энергии составляют лишь 1,3\% [2].

Португалия

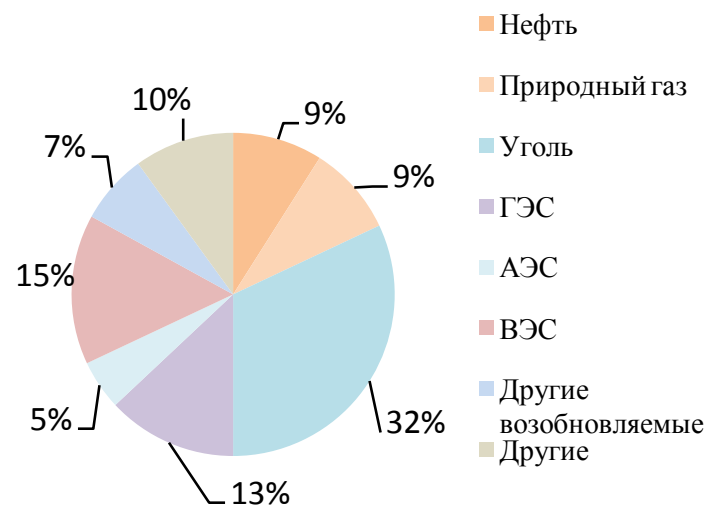

Республика Беларусь

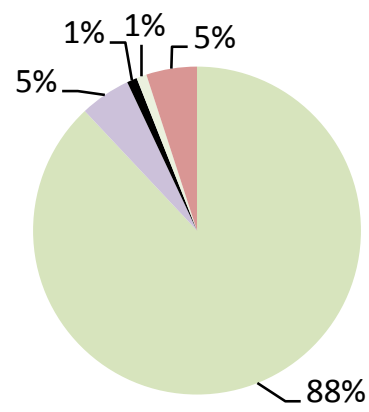

Рисунок 1 - Структура источников энергии Португалии и Республики Беларусь. Источник: составлено автором по $[1,2]$.

Таким образом, несмотря на схожее количество населения и уровень ВВП, энергетические рынки двух стран сильно различаются, 
что объясняется различными геополитическими и природноклиматическими условиями.

Тарифы на электроэнергию в Португалии исторически регулировались государством. Этим занималось специальное учреждение Регулятор - Entidade Reguladora dos Serviços Energéticos (ERSE), что в переводе на русский означает «Управление по регулированию энергетических услуг», а на рынке действовали две компаниимонополисты - EDP и Galp. Поскольку страна небольшая, в ней действует единая сетка тарифов (кроме автономных островных регионов - Мадейра и Азорские острова). Число клиентов энергокомпаний оценивается в 5 миллионов пользователей. И, несмотря на государственное регулирование тарифов для населения, они ежегодно повышались. Так, в середине декабря 2013 года ERSE утвердило повышение цены за киловатт для населения с 1 января 2014 года на 2,8\%. По данным ERSE, средний счет за свет в стране составляет 46,5 евро в месяц.

Сейчас в Португалии в соответствии с требованиями Еврокомиссии проходит энергореформа. Государство планирует отказаться от регулирования тарифов, создав конкуренцию на рынке поставщиков электроэнергии. Предполагается, что конкуренция поможет снизить тарифы. Так же энергореформа - одно из условий финансовой помощи МВФ, так как из-за высоких цен на электроэнергию португальские предприятия менее рентабельны. Переход на свободный рынок является обязательным для всех потребителей до конца 2016 года.

Как создавалась конкуренция? Если раньше в стране был единственный монопольный поставщик электроэнергии для населения компания EDP (Energias de Portugal, ранее называлась Electricidade de Portugal), то теперь эти услуги могут оказывать также Endesa, Galp, Iberdrola и Fenosa. Регулируемые тарифы постепенно, в несколько стадий, отменяются, и потребителей обязывают перейти на свободный рынок, где цены определяют сами предприятия-поставщики (EDP, Galp, Endesa и др.).

На данный момент на рынке электроэнергии существуют различные кампании, предлагающие тарифные планы [3], которые приведены в таблице 1 . 
Таблица 1 - Тарифные планы энергоснабжающих компаний Португалии

\begin{tabular}{|c|c|c|c|}
\hline Компания & Предложение & Потребитель & Скидка \\
\hline $\begin{array}{l}\text { EDP } \\
\text { Comercial }\end{array}$ & $\begin{array}{l}\text { Совместный счет на газ и } \\
\text { электроэнергию с } 10 \% \text {-й } \\
\text { скидкой на газ и 2\%-й } \\
\text { скидкой на } \\
\text { электроэнергию }\end{array}$ & $\begin{array}{l}\text { Частные потребители и } \\
\text { мелкие предприятия с } \\
\text { законтрактованной } \\
\text { мощностью отребления } \\
\text { электроэнергии до } \\
20,7 \text { квт и годовым } \\
\text { потреблением газа до } \\
500 \text { м }^{3}\end{array}$ & $\begin{array}{l}\text { Предоставляется: на } \\
\text { сумму за реально } \\
\text { потребленную энергию } \\
\text { вместе с НДС и } \\
\text { ежемесячной платой за } \\
\text { законтрактованную } \\
\text { мощность, но без налогов } \\
\text { и пошлины за радио- и } \\
\text { телевизионную точку }\end{array}$ \\
\hline EDP Casa & $\begin{array}{l}\text { 2\%-я скидка на } \\
\text { электроэнергию }\end{array}$ & $\begin{array}{l}\text { Частные потребители и } \\
\text { мелкие предприятия с } \\
\text { законтрактованной } \\
\text { мощностью отребления } \\
\text { электроэнергии до } \\
20,7 \text { квт }\end{array}$ & $\begin{array}{l}\text { На сумму за реально } \\
\text { потребленную энергию } \\
\text { вместе с ндс и } \\
\text { ежемесячной платой за } \\
\text { законтрактованную } \\
\text { мощность, но без налогов } \\
\text { и пошлины за радио- и } \\
\text { телевизионную точку }\end{array}$ \\
\hline Galp On & $\begin{array}{l}\text { Совместный счет на газ и } \\
\text { электроэнергию с 5\%-ной } \\
\text { скидкой на газ и 5\%-ной } \\
\text { скидкой на } \\
\text { электроэнергию или } 10 \% \text { - } \\
\text { ной скидкой на газ и } \\
\text { электроэнергию } \\
\text { (посредством } \\
\text { дополнительной платы). } \\
\text { Также возможна скидка в } \\
\text { размере } 2 \% \text { или } 8 \%, \text { если } \\
\text { заключить договор только } \\
\text { на поставку, } \\
\text { соответственно, газа или } \\
\text { электроэнергии }\end{array}$ & $\begin{array}{l}\text { Частные потребители и } \\
\text { мелкие предприятия с } \\
\text { законтрактованной } \\
\text { мощностью } \\
\text { потребления } \\
\text { электроэнергии до } \\
20,7 \text { квт и годовым } \\
\text { потреблением газа до } \\
500 \text { м³ }^{3}\end{array}$ & $\begin{array}{l}\text { На сумму за реально } \\
\text { потребленную энергию } \\
\text { вместе с ндс и } \\
\text { ежемесячной платой за } \\
\text { законтрактованную } \\
\text { мощность, но без налогов } \\
\text { и пошлины за радио- и } \\
\text { телевизионную точку }\end{array}$ \\
\hline Endesa & $\begin{array}{l}\text { 5\%-я скидка на } \\
\text { электроэнергию }\end{array}$ & $\begin{array}{l}\text { Частные потребители и } \\
\text { мелкие предприятия с } \\
\text { законтрактованной } \\
\text { мощностью } \\
\text { потребления } \\
\text { электроэнергии } \\
\text { до 20,7 квт }\end{array}$ & $\begin{array}{l}\text { Только на сумму реально } \\
\text { потребленной энергии } \\
\text { вместе с ндс }\end{array}$ \\
\hline Goldenergy & 20\%-я скидка на газ & Любые клиенты & \\
\hline
\end{tabular}

Источник: составлено автором по [3, 4]. 
Каждая компания имеет свой набор тарифов, предлагаемых потребителям. Так, Простой тариф представляет собой фиксированную цену за кВт·ч., Двухставочный тариф представляет собой две цены на кВт•ч, зависящие от времени использования: в часы пик, либо - в «низкое» время, то есть время низкого уровня потребления электроэнергии. Пиковые часы - это часы послезакатного вечера и выходные дни, которые являются временем наиболее распространенного использования энергоемких приборов, таких как стиральная машина и посудомоечная машина, духовка или отопление. При выборе этого тарифа предлагается так же выбрать его тип, который не влияет на оплату:

- недельный цикл - это 76 «низких» часов в неделю с понедельника по пятницу, то есть 7 «низких» часов в день, в то время как по субботам это значение составляет 17 часов, а по воскресеньям 24 часа. Этот недельный цикл подойдет тем, кто с большей интенсивностью использует электричество в выходные дни;

- суточный цикл - это 70 «низких» часов, без различий между буднями и выходными днями, всегда по 10 «низких» часов. Этот цикл предназначен для потребителей, которые имеют более равномерное потребление электроэнергии в течение недели.

Необходимо отметить, что, хотя стоимость часов «высокого» потребления энергии немного выше, чем Простой тариф, успехи по экономии, достигнутые в часы пик, составляют около 40 \%, что являет собой значительную часть трат.

При заключении контракта потребитель выбирает мощность, которую он запрашивает на свое жилье или производство. Так, типовая законтрактованная мощность для квартиры составляет 3,45 кВт.ч, для частного дома 4,6 - 6,9 кВт·ч. Для производств возможен выбор мощности вплоть до 41,4 кВт·ч.

Рассчитаем тарифные планы (Простой и Двухставочный) всех представленных поставщиков электроэнергии в зависимости от законтрактованной мощности и в соответствии с потреблением в месяц (таблица 2). Указанные суммы приведены с учетом НДС, без налогов и пошлины за радио- и телевизионную точку. 
Экономика и управление народным хозяйством

Таблица 2 - Тарифы на электроэнергию для частных потребителей

\begin{tabular}{|l|l|l|l|l|}
\hline \multicolumn{1}{|c|}{ Тариф } & Простой & Двухставочный & Простой & Двухставочный \\
\hline $\begin{array}{l}\text { Законтрактованная } \\
\text { мощность, кВт }\end{array}$ & 3,45 & 6,9 & 4,6 & 6,9 \\
\hline Потребление в месяц, кBт·ч & 100 & 120 & 430 & 780 \\
\hline $\begin{array}{l}\text { 1. EDP Serviçо Universal, } \\
\text { eвро }\end{array}$ & 24,26 & 30,83 & 82,04 & 136,21 \\
\hline 2. EDP Casa, eвро & 24,13 & 32,36 & 80,39 & 142,92 \\
\hline $\begin{array}{l}\text { 3. EDP Casa Total 10+2 } \\
\text { (с газом), евро }\end{array}$ & 23,78 & 32,36 & 80,39 & 142,92 \\
\hline 4. Galp 2\%, евро & 23,77 & 32,36 & 80,39 & 142,92 \\
\hline 5. Galp 5\% (с газом), евро & 23,00 & 31,37 & 77,93 & 138,50 \\
\hline 6. Еndesa, евро & 23,37 & 31,98 & 78,35 & 139,16 \\
\hline Среднее значение & 23,72 & 31,88 & 79,92 & 140,44 \\
\hline Отклонения & $\begin{array}{l}-3 \% \\
+2 \%\end{array}$ & $\begin{array}{l}-3 \% \\
+1,5 \%\end{array}$ & $\begin{array}{l}-2,4 \% \\
+2,7 \%\end{array}$ & $\begin{array}{l}-3 \% \\
+1,8 \%\end{array}$ \\
\hline
\end{tabular}

Источник: составлено автором по [3, 4]

Анализируя данную выборку тарифов, надо отметить, что все поставщики предлагают примерно одинаковую цену за предоставленную электроэнергию, однако для некоторых потребителей колебания цены в примерно 5\% могут помочь сделать выбор в пользу той и иной компании. Так же по уровню цены можно судить об ориентации компании в пользу больших или малых потребителей. Так, тарифная политика компании EDP показывает более дешевые тарифы для высокой мощности и большого потребления, в то время как компании Gapl и Endesa ориентированы на привлечение малых потребителей с бытовой мощностью и средним потреблением.

Расчет платы за электроэнергию, воду и газ рассмотрим на конкретном примере двухкомнатной квартиры метражом 88 кв. метров с одним проживающим потребителем.

C компанией EDP заключен контракт по Простому тарифу на предоставляемую мощность в 3,45 кВт·ч (группа низкого напряжения). Надо отметить, что обычно в счет за электроснабжение входят еще платежи за телевидение, радио и специальный налог на эти услуги. Рассмотрим наиболее общий случай современных городских квартир антенновый счетчик (вместе с электрощитом находится в квартире). Цены на электроэнергию свободные [4].

Рядовой счет за электроэнергию компании EDP делится на две части переменную и постоянную. Переменная зависит от количества потребленных киловатт, а постоянная включает ежемесячные фиксированные платежи. Как правило, если потребители не передают сами данные электросчетчика по телефону или через интернет, 
EDP рассчитывает сумму ежемесячного платежа самостоятельно, опираясь на данные за прошедший год. Раз в квартал сотрудник EDP проводит личный осмотр счетчика и счета корректируются. Если потребление оказалось меньше, клиенту засчитывается кредит, если больше, то приходится доплачивать. В данном случае счетчик исправен и каждый месяц (не календарный, а отсчитывая от даты заключения контракта) передаются точные данные о потреблении.

- Переменная часть.

1. Согласно установленному государством тарифу, один киловатт у EDP стоит 0,1587 евро.

2. Каждый потребленный киловатт облагается специальным экологическим налогом, введенным с января 2012 года. Размер налога 0,001 евро за киловатт.

3. Итого получается 0,1597 евро за киловатт. Эта сумма облагается НДС, который составляет $23 \%$.

В итоге стоимость одного киловатта составляет 0,1964 евро.

- Постоянная часть.

В Португалии счет за свет не ограничивается платой за потребленные киловаттами. Он включает также:

4. Платеж за мощность. Рассчитывается в евро в день, то есть не зависит от количества потребленной электроэнергии. Существует шкала мощностей, которые можно подключить бытовому потребителю. Каждой мощности соответствует свой тариф, регулируемый государством. Наиболее распространенный случай - контракт на 3,45 кВт·ч. Тариф: 0,1561 евро в день. Эта цифра умножается на количество дней в месяце и облагается НДС по ставке $23 \%$.

5. Налог на эксплуатацию счетчика устанавливает Генеральная дирекция энергетики и геологии, своего рода португальское министерство энергетики. Налог составляет 0,07 евро в месяц и облагается НДС по ставке $23 \%$.

6. Налог на телевидение. Это форма финансирования государственного телевидения и радиовещания - компании RTP. Налог составляет 2,65 евро в месяц и облагается НДС по льготной ставке $6 \%$. (2,81 евро с НДС). Есть только одна категория потребителей, которые освобождены от уплаты налога - это домохозяйства, потребляющие менее 400 киловатт в год.

Если в квартире не подключено телевидение, как в рассматриваемом нами случае, данная статья расходов отсутствует. В итоге, постоянная часть счета за электроэнергию, фактически платеж за право пользоваться электричеством, составляет - 5,85 евро в месяц.

Также необходимо отметить, что каждая квитанция об оплате содержит информацию о том, из каких источников получена используемая 
энергия. Так, в типовом расчете используется электроэнергия: $54,80 \%$ - ветряные станции, 21,07\% - ГЭС, 10,70\% - ископаемые источники (газ, уголь), $6,70 \%$ - другие возобновляемые источники энергии и $15,10 \%$ - остальные. Это не влияет на цену, но дает представление об экологичности отечественного производства электроэнергии.

При среднем расходе 100 кВт в месяц сумма оплаты за электроэнергию составляет 5,85 + 100 х 0,1964 = 25,49 евро. При этом удельный вес постоянной части - $22,95 \%$ от стоимости оплаты за электроэнергию.

В Республике Беларусь действует своя система тарификации оплаты населением за электрическую энергию. Тарифы отличаются в зависимости от того, какими плитами оборудованы квартиры (газовыми или электрическими), есть одноставочные и двухставочные тарифы, дифференциорованные в зависимости от временных периодов или от объемов энергопотребления. Есть субсидируемые и экономически обоснованные тарифы. Если сравнивать с тарифами для населения, установленными в Республике Беларусь на 01.04.2016, то по курсу 22828 рублей за евро субсидируемый одноставочный тариф составляет 1009,8 рублей за кВт·ч $(0,0442$ евро за кВт·ч), а экономически обоснованный 1900,0 рублей за кВт·ч $(0,0832$ евро за кВт·ч). При оплате 100 кВт·ч потребитель оплачивает 4,42-8,32 евро. То есть тарифы на электроэнергию в Португалии примерно в 3,26-5,77 раза выше, чем, в Республике Беларусь.

Затраты на оплату 100 кВт·ч электроэнергии в Португалии и Республике Беларусь представлены на рисунке 2.

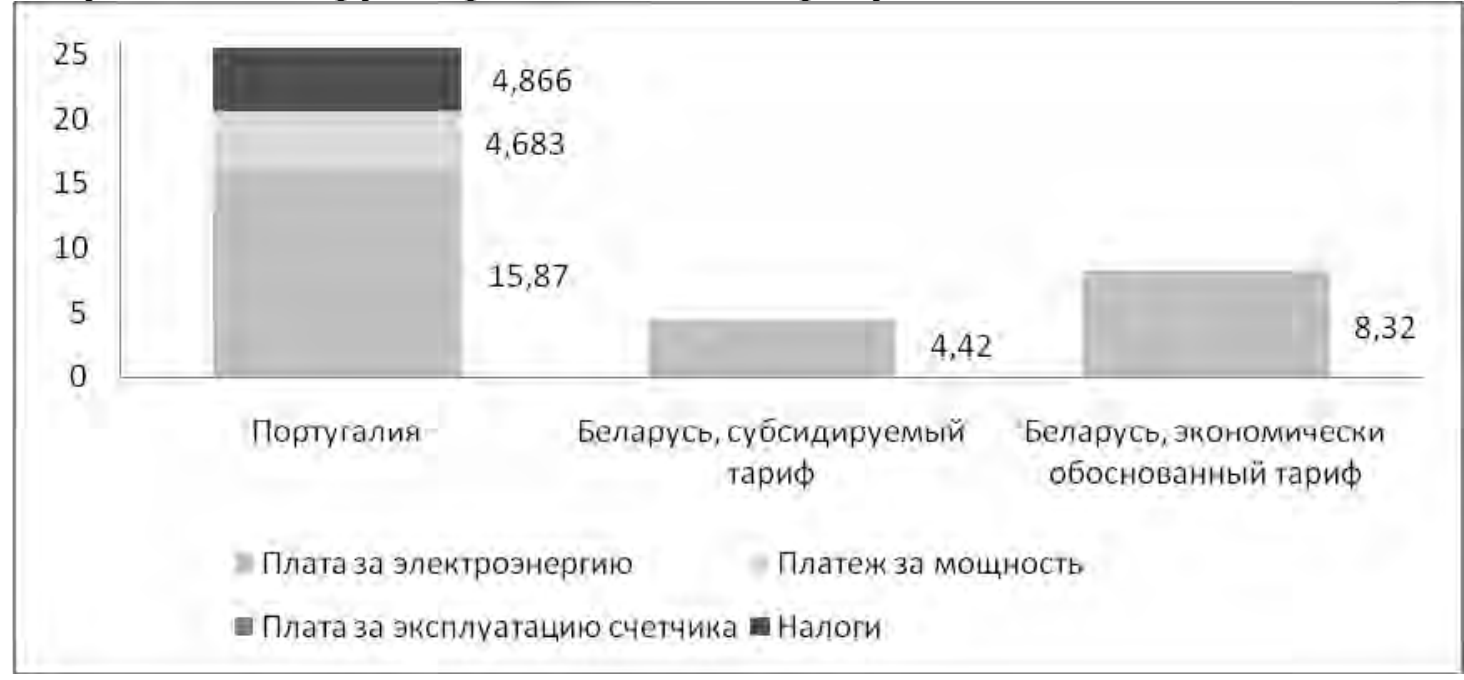

Рисунок 2 - Структура затрат на оплату электрической энергии Португалии и Республики Беларусь, евро. Источник: собственная разработка 
При наглядном различии как структуры затрат на электроэнергию, так и уровня затрат необходимо отметить, что номинальная начисленная зарплата в Республике Беларусь за 2015 год составила 6718697 рублей (294, 32 евро), при этом коммунальные платежи составили 3,2\% доходов населения. При месячной номинальной зарплате в Португалии 1005,17 платежи за электроэнергию, газ и воду составляют 6,3\% доходов населения.

\section{ВЫВОДЫ}

Сравнивая стоимость оплаты электроэнергии в Португалии и Республике Беларусь, можно сделать следующие выводы:

1. Стоимость услуг электроснабжения в Португалии формируется по многоступенчатой системе, которая учитывает отдельно оплату выработки электроэнергии (плата за электроэнергию), использования распределительных сетей (платеж за мощность) и обслуживание потребителей (плата за эксплуатацию счетчика). Это позволяет объективно учитывать интересы всех участников процесса энергоснабжения и гибко управлять энергопотреблением.

2. Каждый потребитель однозначно понимает, что именно входит в стоимость услуг, и имеет возможность выбирать между различными энергоснабжающими компаниями.

3. Оплата услуг энергоснабжения состоит из двух видов затрат: постоянной - зависящей от установленной мощности и обслуживания электросчетчиков (потребителей) и переменной - платы за потребленную электроэнергию. Такая тарифная система соответствует видам затрат на энергоснабжение: переменные затраты, связанные с объемом поставляемой энергии, и постоянные затраты, связанные с содержанием и обслуживанием сетей электроснабжения.

4. Несмотря на социальный характер оказываемых услуг, каждая составляющая тарифа облагается налогами, в первую очередь НДС, ставка которого составляет $23 \%$.

5. В Республике Беларусь также есть одноставочные и двухставочные тарифы для населения, которые дифференцированы по объемам потребления и по временным периодам. Тарифы зависят от того, оборудованы квартиры электрическими или газовыми плитами. Тарифы отражают социальную политику государства, предоставляя основной массе населения услуги электроснабжения по субсидируемым государством тарифам, которые значительно ниже экономически обоснованных затрат на оказание этих услуг. 
6. В Республике Беларусь плата за электроэнергию не разделена в зависимости от структуры затрат на энергоснабжение: производство, передача и обслуживание потребителей, что не позволяет оценить влияние каждого из участников системы энергоснабжения на стоимость конечного продукта.

7. В Республике Беларусь тарифы не учитывают того, что в системе энергоснабжения есть переменные и постоянные затраты, что даже при отсутствии энергопотребления энергоснабжающие организации все равно несут затраты на содержание сетей и установленной мощности. Выделение постоянных и переменных затрат позволяет учитывать специфику затрат и более объективно распределять их на потребителей.

\section{ЛИТЕРАТУРА}

1. Европейская статистическая комиссия // [Электронный pecypc] / Режим доступа: http://ec.europa.eu/

2. Национальный статистический комитет Республики Беларусь // [Электронный ресурс] / Режим доступа: http://www.belstat.gov.by/

3. Сайт компании EDP. // [Электронный ресурс] / Режим доступа: https://edponline.edp.pt/

4. Сайт компании Регулятора энергетических услуг // [Электронный ресурс] / Режим доступа: http://www.erse.pt/

Статья поступила в редакиию 18 мая 2016 года. 